\title{
Biomarkers for Acute Respiratory Distress syndrome and prospects for personalised medicine
}

\author{
Savino Spadaro ${ }^{1}$, Mirae Park², Cecilia Turrini ${ }^{1}$, Tanushree Tunstall ${ }^{2}$, Ryan Thwaites ${ }^{2}$, Tommaso Mauri ${ }^{3}$, \\ Riccardo Ragazzi ${ }^{1}$, Paolo Ruggeri ${ }^{4}$, Trevor T. Hansel ${ }^{2}$, Gaetano Caramori ${ }^{4}$ and Carlo Alberto Volta ${ }^{1 *}$ (D)
}

\begin{abstract}
Acute lung injury (ALI) affects over 10\% of patients hospitalised in critical care, with acute respiratory distress syndrome (ARDS) being the most severe form of ALI and having a mortality rate in the region of $40 \%$. There has been slow but incremental progress in identification of biomarkers that contribute to the pathophysiology of ARDS, have utility in diagnosis and monitoring, and that are potential therapeutic targets (Calfee CS, Delucchi K, Parsons PE, Thompson BT, Ware LB, Matthay MA, Thompson T, Ware LB, Matthay MA, Lancet Respir Med 2014, 2:611--620). However, a major issue is that ARDS is such a heterogeneous, multi-factorial, end-stage condition that the strategies for "lumping and splitting" are critical (Prescott HC, Calfee CS, Thompson BT, Angus DC, Liu VX, Am J Respir Crit Care Med 2016, 194:147--155). Nevertheless, sequencing of the human genome, the availability of improved methods for analysis of transcription to mRNA (gene expression), and development of sensitive immunoassays has allowed the application of network biology to ARDS, with these biomarkers offering potential for personalised or precision medicine (Sweeney TE, Khatri P, Toward precision medicine Crit Care Med; 2017 45:934-939).

Biomarker panels have potential applications in molecular phenotyping for identifying patients at risk of developing ARDS, diagnosis of ARDS, risk stratification and monitoring. Two subphenotypes of ARDS have been identified on the basis of blood biomarkers: hypo-inflammatory and hyper-inflammatory. The hyper-inflammatory subphenotype is associated with shock, metabolic acidosis and worst clinical outcomes. Biomarkers of particular interest have included interleukins (IL-6 and IL-8), interferon gamma (IFN- $\gamma$ ), surfactant proteins (SPD and SPB), von Willebrand factor antigen, angiopoietin 1/2 and plasminogen activator inhibitor-1 (PAl-1). In terms of gene expression (mRNA) in blood there have been found to be increases in neutrophil-related genes in sepsis-induced and influenzainduced ARDS, but whole blood expression does not give a robust diagnostic test for ARDS.

Despite improvements in management of ARDS on the critical care unit, this complex disease continues to be a major life-threatening event. Clinical trials of $\beta_{2}$-agonists, statins, surfactants and keratinocyte growth factor (KGF) have been disappointing. In addition, monoclonal antibodies (anti-TNF) and TNFR fusion protein have also been unconvincing. However, there have been major advances in methods of mechanical ventilation, a neuromuscular blocker (cisatracurium besilate) has shown some benefit, and stem cell therapy is being developed. In the future, by understanding the role of biomarkers in the pathophysiology of ARDS and lung injury, it is hoped that this will provide rational therapeutic targets and ultimately improve clinical care (Seymour CW, Gomez $\mathrm{H}$, Chang CH, Clermont G, Kellum JA, Kennedy J, Yende S, Angus DC, Crit Care 2017, 21:257).
\end{abstract}

Keywords: Acute respiratory distress syndrome, Biomarkers, Inflammatory

\footnotetext{
* Correspondence: vlc@unife.it

'Department of Morphology, Surgery and Experimental Medicine, Intensive

Care Section, University of Ferrara, 44121 Ferrara, Italy

Full list of author information is available at the end of the article
}

(c) The Author(s). 2019 Open Access This article is distributed under the terms of the Creative Commons Attribution 4.0 International License (http://creativecommons.org/licenses/by/4.0/), which permits unrestricted use, distribution, and

reproduction in any medium, provided you give appropriate credit to the original author(s) and the source, provide a link to the Creative Commons license, and indicate if changes were made. The Creative Commons Public Domain Dedication waiver (http://creativecommons.org/publicdomain/zero/1.0/) applies to the data made available in this article, unless otherwise stated. 


\section{Introduction}

\section{Definition of ARDS}

The definition and the criteria for the diagnosis of ARDS have changed many times during the years. The first description of an ARDS-like syndrome appeared in 1967 grouping together patients with acute respiratory failure associated with dyspnea, tachypnea, cyanosis that is refractory to oxygen therapy, decreased lung compliance, and diffuse alveolar infiltrates evident on the chest radiograph [1].

The 1994 American-European Consensus Conference (AECC) defined ARDS according to the presence of all the following clinical criteria: a) recent onset of symptoms after a known risk factor, b) severe hypoxemia defined by a $\mathrm{PaO}_{2} / \mathrm{FiO}_{2}$ ratio less than $200 \mathrm{mmHg}$, c) bilateral infiltrates on chest radiograph, d) absence of cardiogenic pulmonary edema [2]. The AECC coined the term Acute Lung Injury (ALI) to facilitate diagnosing patients earlier in the course of their ARDS and identify patients who have a milder form of acute hypoxemic respiratory failure than ARDS.

The Berlin Clinical Classification of ARDS was established to classify patients according to their disease. The current working definition of proposed three mutually exclusive categories (mild, moderate, severe) of ARDS severity (Table 1). These are based on degree of hypoxemia [3]. In the revised Berlin definition, the term ARDS was redefined as a broader concept including a milder condition of lung injury; therefore, it became equivalent to acute lung injury (ALI), which was the previous AECC definition.

\section{Epidemiology of ARDS}

The acute respiratory distress syndrome (ARDS) represents a major cause of death in the critical care units worldwide, with mortality rates around 40\% [4] even with the latest advances in its treatment $[4,5]$. In recent prospective study carried out in 459 ICUs in 50 countries in 5 continents, ARDS appeared to be underrecognized and undertreated, with some geographic variation and with confirmed high mortality [6]. In this multicenter study ARDS has shown to represent $10.4 \%$ of total ICU admission and $23.4 \%$ of all patients requiring mechanical ventilation. The prevalence of mild ARDS was
$30.0 \%$, moderate, $46.6 \%$ and severe, $23.4 \%$. Overall, unadjusted ICU and hospital mortality was 35.3 and $40.0 \%$, respectively and both augmented with increased ARDS severity [6].

\section{Aetiology of ARDS}

In the Berlin definition ARDS has been defined by exposure to a known clinical insult or worsening of respiratory symptoms within 7 days. Although the exact cause of ARDS is not always determinable, it is important to identify the risk factors associated. Generally, risk factors are divided into direct and indirect causes of lung injury (Table 2). The most common causes of indirect ARDS are pneumonia and sepsis. However, these are not the only drivers that lead to the development of ARDS but other unknown factors play a role in the pathogenesis. Among them genetic factors may be involved although no single gene polymorphism has shown significant predisposition to ARDS. Moreover, virulence factors and environmental ones (such as exposition to injurious mechanical ventilation) may contribute to the progression of the disease to ARDS [7, 8]. An ideal biomarker should provide information for identification of patients at risk for ARDS and with different ARDS phenotypes during the progression of lung injury. Indeed several candidate biomarkers for ARDS that have been investigated in blood, pulmonary edema fluid, and exhaled air, but currently they are not reliable enough for clinical use. A combination of biomarkers could help distinguish patients with direct lung injury from those with an indirect mechanism of lung injury, thus helping in the diagnosis and identification of patients that may benefit from different therapeutic strategies (Table 3).

\section{Pathology}

The pathophysiology of ALI/ARDS is complex and remains incompletely understood.

Interestingly all the above definitions of ARDS do not include the presence of an inflammatory process of the lower airways. Despite this, ARDS is currently considered to represent a stereotypic response to many different injuries all evolving through a number of different

Table 1 Current definition of ARDS: the Berlin definition [3]

\begin{tabular}{|c|c|}
\hline Timing & Within 1 week of a known clinical insult or new or worsening respiratory symptoms \\
\hline Chest imaging (chest radiograph or computed tomography scan) & Bilateral opacities; not fully explained by effusions, lobar/lung collapse, or nodules \\
\hline Origin of edema & $\begin{array}{l}\text { Respiratory failure not fully explained by cardiac failure or fluid overload } \\
\text { Need objective assessment (e.g., echocardiography) to exclude hydrostatic } \\
\text { edema if no risk factor present }\end{array}$ \\
\hline \multirow[t]{3}{*}{ Oxygenation } & $200 \mathrm{mmHg}<\mathrm{PaO}_{2} / \mathrm{FIO}_{2} \leq 300 \mathrm{mmHg}$ with PEEP or CPAP $\geq 5 \mathrm{cmH}_{2} \mathrm{O}$ \\
\hline & $100 \mathrm{mmHg}<\mathrm{PaO}_{2} / \mathrm{FlO}_{2} \leq 200 \mathrm{mmHg}$ with PEEP $\geq 5 \mathrm{cmH}_{2} \mathrm{O}$ \\
\hline & $\mathrm{PaO}_{2} / \mathrm{FlO}_{2} \leq 100 \mathrm{mmHg}$ with PEEP $\geq 5 \mathrm{cmH}_{2} \mathrm{O}$ \\
\hline
\end{tabular}


Table 2 Risk factors commonly associated with ARDS

\begin{tabular}{ll}
\hline Direct lung injury & Indirect lung injury \\
\hline Pneumonia & Sepsis \\
Aspiration of gastric contents & Multiple trauma \\
Pulmonary contusion & Cardiopulmonary bypass \\
Near drowning & Acute pancreatitis \\
Inhalation injury & Drug overdose \\
Reperfusion pulmonary edema & Transfusion of blood products \\
\hline
\end{tabular}

phases: alveolar and capillary damage to lung resolution with or without a fibro-proliferative phase.

Furthermore, ARDS is not characterized by a specific clinic-pathological disease but includes a heterogeneous list of clinic-pathological entities, usually showing diffuse alveolar damage (DAD) with severe widespread damage to the alveolo-capillary unit [9].

\section{Early and late phases of lung injury}

Pathologically and clinically, ARDS can be divided into early and late phases of lung injury, corresponding to exudative and fibroproliferative phases [10] (Fig. 1). This involves endothelial and epithelial damage, the inflammatory cascade, and increased vascular permeability. There are associated alterations in lung matrix, activation of coagulation and fibrosis pathways, with cell proliferation and apoptosis.

A. Early phase: In the early phase (first few hours or days), there is widespread neutrophilic alveolitis

Table 3 Biomarkers of ARDS [13, 15, 92, 93]

\begin{tabular}{lll}
\hline Pathway & Biomarkers & \\
\hline Epithelial & RAGE & \\
& SP-D & \\
& KL-6 & \\
& CC16 & \\
& KGF & \\
Endothelial & Ang-1/2 & \\
& VWF & \\
Inflammatory & VEGF & $\mathrm{IL}-1 \beta$ \\
& Pro-inflammatory & $\mathrm{IL}-6$ \\
& & $\mathrm{TNFa}$ \\
& & $\mathrm{IL}-8$ \\
& & $\mathrm{IL}-18$ \\
& & $\mathrm{IL}-1 \mathrm{RA}$ \\
& Anti-inflammatory & STNF-RI/II \\
& & $\mathrm{IL}-10$ \\
& & \\
\hline
\end{tabular}

with disruption of the alveolar epithelial and endothelial barriers, while leads to the formation of protein-rich edema in the interstitium and alveolar spaces [8]. Microscopically, lungs in the early stages show diffuse alveolar damage (DAD) with alveolar flooding by proteinaceous fluid, neutrophil influx into the alveolar space, loss of alveolar epithelial cells, deposition of hyaline membranes on the denuded basement membrane and formation of microthrombi [11]. Inflammatory cell infiltration of the lung interstitium may also be seen. The alveolar flooding occurs as a result of injury to the alveolar-capillary barrier and is a major determinant of the hypoxemia and altered lung mechanics that characterize early ALI/ ARDS. Injury to the alveolar epithelium is a prominent feature histologically with loss of alveolar epithelial barrier integrity and extensive necrosis of alveolar epithelial type I cells. Endothelial injury allows leakage of plasma from the capillaries into the interstitium and airspace. The mechanism by which the microvascular endothelium and alveolar epithelium are injured are probably multiple and may vary depending on the inciting event.

B. Late Phase: Disordered healing and proliferation of fibrous tissue dominate the late phase of ARDS. The scenario evolves to a fibro-proliferative process that fills the airspaces with granulation tissue containing proliferating alveolar type II cells, as well as new blood vessels and extracellular matrix rich in collagen and fibrin. Type II alveolar cell, fibroblast and myofibroblasts proliferate in this phase, which can occur as early as 7 to 10 days after initial injury. This stage has traditionally been described as being followed by a fibrotic phase, essentially emphasizing the appearance of pulmonary fibrosis in a subset of patients with irreversible lung fibrosis [11]. Recent observations have suggested that the areas of fibrosis may develop sooner than previously appreciated. Elevated levels of $\mathrm{N}$-terminal procollagen peptide III, thought to represent collagen synthesis, can be detected in bronchoalveolar lavage fluid of patients with ARDS as early as $24 \mathrm{~h}$ into the course of the illness [12]. This observation have led some investigators to hypothesize that fibroproliferation may be initiated simultaneously with inflammatory lung injury [12].

\section{Biomarkers}

In ARDS biomarkers have promise in diagnosis and stratification, assessment of prognosis and to evaluate response to therapy [13, 14] (Fig. 2). Sequencing of the human genome, the availability of improved methods for 


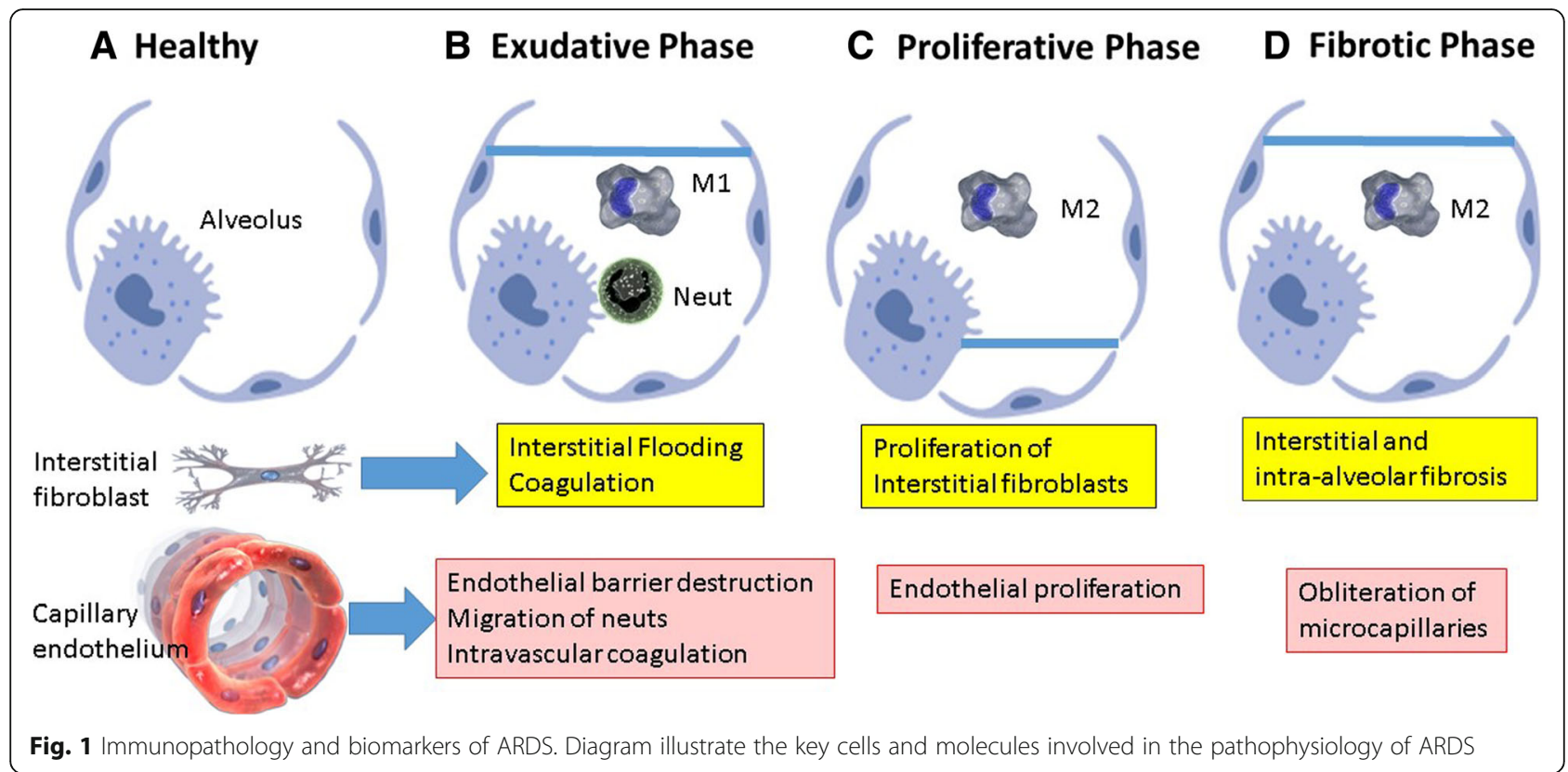

analysis of transcription to mRNA (gene expression), and development of sensitive immunoassays has allowed the application of network biology to ARDS, with these biomarkers offering potential for personalised or precision medicine [15].
Epithelial markers

Respiratory epithelium markers include surfactant proteins (SP); Krebs von den Lungen-6 (KL-6) protein, vascular endothelial growth factor (VEGF) and soluble receptor for advanced glycation end-products (sRAGE)

\section{Exudative Phase}
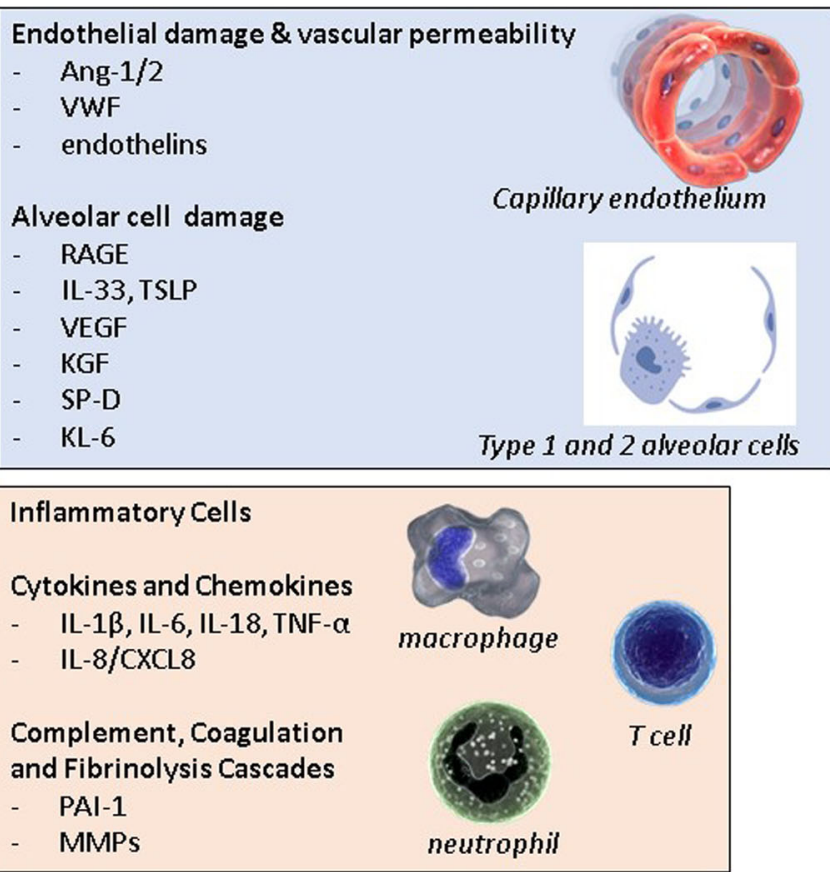

\section{Fibroproliferative Phase}

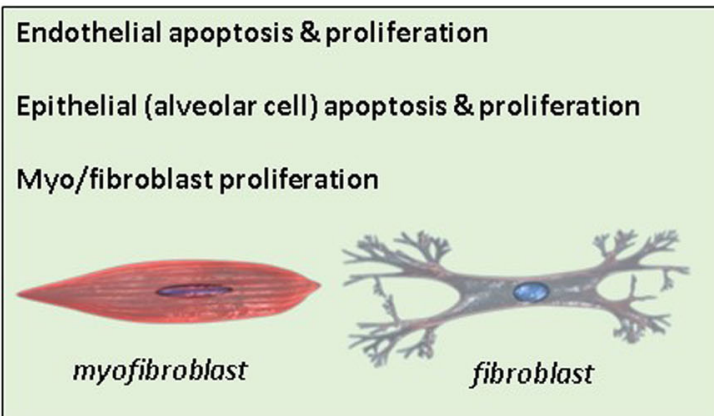

Fig. 2 Diagram to illustrate the Key Cells and Molecules involved in the Immune. Pathophysiology of ARDS: with an emphasis on biomarkers that have been measured in plasma (based on the work of the Carolyn Calfee group) 
- Surfactant proteins (SP) are generally increased in ARDS, and SP-B can cross damaged alveolocapillary membranes [16, 17]. Blood SP-D levels been shown to correlate with ARDS mortality $[18,19]$.

- KL-6 levels have been correlated with ARDS mortality as opposed to ARDS development [20]. In 2014 a meta-analysis of plasma biomarkers for ARDS analysed 54 studies found KL-6, lactate dehydrogenase, sRAGE, and von Willebrand factor were associated with ARDS diagnosis in at risk populations [21].

- VEGF and keratinocyte growth factor were shown to correlate with severity of illness and reflect patient outcome [22, 23].

- RAGE is highly expressed in lung epithelium [24], and especially expressed on alveolar type 1 epithelial cells [25]. The use as a marker has been questionable but some studies have shown higher levels of RAGE were associated with impaired alveolar fluid clearance in patients with ARDS hence the severity of lung epithelial injury [26]. RAGE plasma levels in patients with severe ARDS correlated with mortality in patients ventilated with high tidal volumes [27]. In a meta-analysis sRAGE was found to be useful in ARDS diagnosis in a high risk population, but not associated with mortality [21], although other studies have shown no association $[28,29]$.

\section{Endothelial markers}

Endothelial markers include angiopoietin-2 (Ang-2) and markers of endothelial dysfunction [30]. Elevated levels of Ang-2 in both ARDS and at risk patients are predictive of mortality $[29,31,32]$ and there is a correlation between Ang-2 levels and ARDS development in trauma patients [33]. In addition, for VWF here seems to be a correlation with mortality in ARDS [18, 34, 35].

\section{Inflammatory cytokines}

Levels of the inflammatory cytokines IL-1 $\beta$ and TNF- $\alpha$ are more useful as markers of sepsis severity rather than for ARDS [36]. Other pro-inflammatory cytokines include IL-8, which has been shown in predicting the outcome of ARDS [18, 34]. IL-18 has been noted to be increased in patients with ARDS, and been associated with mortality [37]. An external validation of biomarkers and a clinical prediction model for hospital mortality in ARDS included SP-D and IL8 in various clinical settings, and suggested that these biomarkers may be useful in risk assessment for clinical trial enrolment [38].

\section{Coagulation and fibrinolysis}

Plasminogen activator inhibitor-1 (PAI-1) is an inhibitor of fibrinolysis. Some studies have shown an increase in serum levels in patient with ARDS $[18,39,40]$, and there is reported correlation with overall mortality in critically ill patients [41].

\section{Combinations of biomarkers}

Several studies have looked into markers of epithelial and endothelial injury, coagulation and inflammation and have shown a combination of clinical predictors with combination of biomarkers were better at predicting mortality compared to either of the clinical or biomarkers alone [18, 33, 34, 42]. A panel of biomarkers was superior to clinical risk factors alone in predicting mortality in ARDS [18], as well as being useful for the diagnosis of ARDS [27]. A combination of RAGE and Ang-2 were superior to clinical diagnosis for the diagnosis of ARDS in severe trauma [43]. In severe sepsis a panel which included RAGE, SPD, Club Cell Protein 16 was useful in diagnosis of ARDS [42].

\section{Blood biomarkers of ARDS: Calfee group, SF}

In recent years the clinical research group of Carolyn Calfee and colleagues have performed clinical studies assessing panels of blood biomarkers in ARDS. In the era of precision medicine and personalization, the Calfee group studies proceed on a more detailed characterization of the disease that may vary on individual level. They describe different ARDS subphenotypes and work on biomarker panels that may help clinicians to select patients who may benefit from different therapeutic strategies.

Direct (epithelial)/Indirect (endothelial) Groups: Molecular phenotyping was carried out to demonstrate 2 groups of ARDS patients: with direct (lung epithelial) damage and indirect (vascular endothelium) damage. Direct lung injury mainly caused by pneumonia and aspiration is characterised by more severe lung epithelial injury and less severe endothelial injury. For indirect lung injury, the emphasis is on endothelial or vascular injury, as opposed to epithelial damage. In direct ARDS, there are higher levels of SP-D, a marker of lung epithelial damage and there were lower levels of Ang-2, a marker of endothelial injury compared to indirect ARDS. There is evidence that lower levels of von Willebrand factor (VWF) antigen, IL6 and IL8 are present in direct lung injury [44]. With these distinct molecular phenotypes, the epithelium could be a treatment target with keratinocyte growth factor for direct ARDS, whereas the endothelium could be targeted in indirect ARDS using statins and recombinant angiopoietin 1 [44].

Hypo/Hyper Inflammatory Groups: Unbiased latent class analysis of clinical and biomarkers characteristics of ARDS patients demonstrated hypo-inflammatory and hyper-inflammatory groups in ARDS. These have different clinical and biological characteristics, and different responses to therapy. In the hyperinflammatory group 
(one third of ARDS subjects), there is a higher plasma level of inflammatory biomarkers, higher vasopressor use and lower serum bicarbonate, and higher prevalence of sepsis compared to the hypo-inflammatory group. The hyper-inflammatory group had a higher mortality and fewer ventilator-free and organ failure-free days. Eight plasma biomarkers were included: surfactant protein-D (SP-D), von Willebrand factor antigen, soluble intercellular adhesion molecule 1 (sICAM-1), IL- 6 and IL-8, soluble tumor necrosis factor receptor 1 (TNFR 1), plasminogen activator inhibitor-1 (PAI-1) and protein C [13]. More recently, it has been shown that a selection of 4 biomarkers: IL-6, interferon gamma (IFN- $\gamma$ ), angiopoietin $1 / 2$ and PAI-1 could be used to cluster ARDS into two biological phenotypes with different mortality rates [45]. The stability of ARDS phenotypes has been shown over the first 3 days of enrolment in 2 clinical trials [46], and they respond differently to fluid management strategies [47].

\section{Septic shock biomarkers: ProCESS study}

A large biomarker study of 1341 individuals enrolled in the Protocolized Care of Early Septic Shock (ProCESS) trial found that proteins associated with endothelial cell permeability and hemostasis were associated with increased mortality [48]. Angiopoietin-2, soluble fms-like tyrosine kinase 1 (sFLT-1), soluble vascular endothelial growth factor receptor (s-VEGFR), thrombomodulin (TM) and vWF were all higher in patients that died. In a sub-study of 628 patients enrolled in ProCESS, higher serum biomarkers were found in patients with adverse outcomes: including biomarkers of inflammation (IL-6, TNF, IL-10), coagulation (thrombin-antithrombin complex, D-dimer), oxidative stress (urine isoprostane) and tissue hypoxia (lactate) [49].

\section{Influenza ARDS: MOSAIC}

The H1N1 influenza A virus is known to be associated to high morbidity and mortality. The infection can cause a severe acute respiratory failure or ARDS with multiorgan failure. The H1N1 pandemic of 2009 saw many cases of severe ARDS with refractory hypoxemia that needed the veno-venous extracorporeal membrane oxygenation as a rescue therapy [50, 51]. Recently, the interferon-inducible transmembrane (IFITM3) protein has shown in models to have a pivotal role in defending the host from pathological virus such as influenza A. In human individuals hospitalized for influenza H1N1/2009 virus it has been found elevated expression of a minor IFITM3 allele and in vitro minor CC genotype IFITM3 has reduced influenza virus restriction [52].

\section{Metabolomics}

The analysis of lower molecular weight cell metabolites is generally performed using nuclear magnetic resonance
(NMR) and mass spectrometry (MS). Metabolic changes are highly dynamic and offer insight into chemical processes occurring at any given time [53]. This makes metabolomics a useful way to detect physiological changes in real time allowing monitoring of potential environmental insults, disease progression and drug responses. These metabolite changes occur in relation to alterations in the gene and protein activity that are associated with the disease [54]. In a single study there were 4513 metabolites identified in human blood but this is an underestimate based on the individual analytical method [55]. Although many studies have been performed to assess the application of metabolomics to lung disease, progress has been slow [54].

There have been several metabolomics studies in experimental models looking at a variety of samples from exhaled breath, serum, bronchial alveolar lavage and lung tissue which find that lung injury results in a perturbation of energy and oxidative stress metabolism [54]. In contrast, there have been few clinical metabolomics studies in ARDS. Bos et al. looked into exhaled breath and analysing volatile organic compounds (VOCs) using gas-chromatography and mass spectrometry (GC-MS). Most of the candidate markers are linked to lipid peroxidation. Only octane - one of the end products of lipid peroxidation - has been validated in a temporal external validation cohort and is at the moment is most acknowledged breath biomarker for ARDS [56]. Acetaldehyde and 3-methylheptane have also been reported as predictive of ARDS and diagnostic accuracy was improved with the Lung Injury Prediction Score (LIPS) [56].

Metabolomic analysis of bronchoalveolar lavage (BAL) has been carried out using untargeted liquid chromatography mass spectrometry (LC-MS). Metabolites involved with energy metabolism such as lactate, citrate, creatine and creatinine have been shown to be associated to ARDS, and have previously been shown to be increased in plasma [57]. In addition, several guanosine network metabolites have been found to be increased in ARDS BAL fluid [54].

Langley et al. looked at extensive targeted metabolomics profiling of $>300$ metabolites in two adult populations at high risk of death; patients in Community Acquired Pneumonia and Sepsis Outcome Diagnostics (CAPSOD) and patients in the Registry of Critical Illness (RoCI) [58]. Despite the phenotypic differences, most metabolites associated with mortality were upregulated.

The application of NMR-based metabolomic analysis on urine sample of pneumonia patients demonstrated the existence of different metabolomic profiles specific for bacterial infections, particularly for Streptococcus pneumoniae and Staphylococcus aureus. The results highlight the potential of metabolomics for the diagnosis and monitoring of the antibiotic therapy of pneumonia both in community- and hospital-acquired ones [59]. 
In ARDS patients higher urine $\mathrm{H}_{2} \mathrm{O}_{2}$ levels were associated with worse clinical outcomes, perhaps reflecting greater oxidative injury in these patients [60]; while higher urine NO levels were associated with increased survival [61]. Urinary indices of glycosaminoglycan (GAG) fragmentation, a product of degradation of the endothelial glycocalyx, individuated by mass spectrometry on urine samples in patients with septic shock or ARDS may predict acute kidney injury and in-hospital mortality [62].

\section{Transcriptomics - Gene expression mRNA}

A recent multicohort analysis of whole blood gene expression data for ARDS by Sweeney et al. looked into 3 adult cohorts with sepsis, one paediatric cohort with acute respiratory failure and 2 datasets form adults with trauma and burns for a total of 148 cases of ARDS and 268 cases of critically ill controls. 30 genes were associated with ARDS - many of which have previously been associated with sepsis but with adjustment for the clinical severity score - none of these genes remained significant indicating that the gene expression is one of acute inflammation as opposed to lung injury [63].

Sweeney also looked separately into sepsis subtypes using data pooled from 14 bacterial sepsis transcriptomics $(n=700)$. Using cluster analysis Sweeney showed that there are 3 subtypes termed 'inflammopathic, adaptive and coagulopathic'. Adaptive subtypes are associated with lower clinical severity and lower mortality rate and the coagulopathic subtypes are associated with higher mortality and clinical coagulopathy [64].

\section{MicroRNA (MiRNA)}

MiRNA is a novel pathway for non-coding RNA molecules that regulate gene expression at the post-transcriptional level. It plays an important role in inflammation or apoptosis which commonly manifests in ARDS [65]. They are good candidates as disease biomarkers due to numerous factors. They can be identified in various body fluids, resistant to extreme environmental conditions, their expression changes in various disease states and change in early stages of gene expression. MiRNA can be readily measured and hence are potential therapeutic targets as each miRNA regulates the expression of many genes [66]. Most of the studies to date have been on animal models but one of the first miRNA studied in patients was miRNA-150 which has been shown to be in lower concentrations in the septic cohort; although statistical significance was not achieved [67]. Plasma levels of miRNA - 146a and miRNA155 significantly increased in patients with severe sepsis and sepsis induced ALI compared to control [68] and may be helpful in predicting mortality. A more recent study by Zhu et al. examined ARDS patients' vs critically ill at-risk controls and identified whole blood miRNA markers in ARDS including miR-181a, miR92a. MiR-424 was shown to be a protective biomarker. Zhu concluded stating in addition to the miRNA, addition of the LIPS can improve the risk estimate of ARDS [69].

\section{Genetics (DNA)}

Genomics in ARDS has offered relatively modest advances in understating ARDS [53]. Candidate gene studies have identified variants in more than 40 candidate genes associated with the development (or outcome) of ARDS [70]. This included genes for angiotensin-converting enzyme (ACE), IL-10, TNF and vascular endothelial growth factor (VEGF). In the first human genome-wide association study (GWAS) for ARDS susceptibility, Christie et al. identified a novel locus PPFIA1 as a replicable risk factor for ALI following major trauma, but no polymorphism had genome wide significance [71].

\section{Therapies}

Current therapies for ARDS are summarized in Table 4. The reader is directed to excellent recent reviews that refer to modern treatment for ARDS in detail [7, 72-74]. Most advances have been through changes in mechanical ventilation methods, culminating in a 2017 International Clinical Practice Guideline for mechanical ventilation on adults with ARDS [75]. The guidelines address 6 interventions: low tidal volume and inspiratory pressure ventilation, prone positioning, high-frequency oscillatory ventilation, higher versus lower positive end-expiratory pressure, lung recruitment manoeuvres, and extracorporeal membrane oxygenation. Otherwise treatment is supportive and palliative, with no current disease-modifying therapies available. Early goal-directed therapy (EGDT) involving a $6 \mathrm{~h}$ resuscitation protocol of fluids, vasopressors, inotropes and red cell transfusion for septic shock did not result in better outcomes than usual care [76].

Glucocorticoids may improve oxygenation and airway pressures in established ARDS, but have failed to demonstrate a role in preventive therapy. In patients with pneumonia, steroids may improve radiological appearances, but again does not improve mortality [77]. Trials conducted on established ARDS investigated different doses and duration of treatment, preventing generalization of the results, however analysis suggest that if steroids are started 14 days or more after the diagnosis of ARDS, they can be harmful. The combination of inhaled $\beta_{2}$-agonists and glucocorticoid administered early in patients at risk of ARDS has recently shown to prevent development of ARDS and improve oxygenation but its effect on mortality has not been demonstrated [78].

Pre-hospital aspirin has been shown to reduce the incidence of ARDS, however results of ongoing trials 
Table 4 Summary of therapies for acute respiratory distress syndrome

\begin{tabular}{|c|c|}
\hline Supportive therapy & Comment \\
\hline $\begin{array}{l}\text { Lung protective ventilation with low tidal volume }(4-8 \mathrm{ml} / \mathrm{kg} \text { predicted } \\
\text { body weight) and low inspiratory pressures (plateau pressure } \\
\left.<30 \mathrm{CmH}_{2} \mathrm{O}\right)\end{array}$ & Strong recommendation [75] \\
\hline Higher level of PEEP ${ }^{\S}$ in patients with moderate or severe ARDS & Conditional recommendation [75] \\
\hline Lung recruitment maneuvers in patients with moderate or severe ARDS & Conditional recommendation [75] \\
\hline Prone positioning for more than $12 \mathrm{~h} /$ die in patients with severe ARDS & Strong recommendation [75] \\
\hline HFOV & Strong recommendation against the routine use of HFOV [75] \\
\hline ECMO & $\begin{array}{l}\text { Rescue therapy for refractory hypoxemia in severe ARDS. No } \\
\text { recommendation is made, additional studies are needed [75]. }\end{array}$ \\
\hline Conservative fluid management strategy & $\begin{array}{l}\text { It shortened the duration of assisted ventilation in large randomized } \\
\text { trial }[94,95]\end{array}$ \\
\hline
\end{tabular}

Pharmacological therapy

Glucocorticoids

Inconclusive results on doses and duration of treatment. May provide some benefit on oxygenation, reduce inflammatory process and ventilation days. They are harmful if started 14 days after ARDS diagnosis [96].

Inhaled nitric oxide (NO)

Improves transiently oxygenation. Does not affect mortality. Higher grade of AKI [80].

Neuromuscolar blockade

Improve outcomes in patients with moderate to-severe ARDS, ensures patient-ventilator synchrony and reduces the risk of VILI [81]. Higher risk of diaphragm atrophy and ICU acquired weakness. Ongoing trial (NCT02509078).

Mesenchimal stem cells

Phase 2a clinical trials to establish safety in ARDS are in progress and two phase 1 trials did not report any serious adverse events [81].

${ }^{5}$ PEEP positive end-expiratory pressure, ARDS acute respiratory distress syndrome, $H F O V$ high frequency oscillatory ventilation, ECMO extra-corporeal membrane oxygenation, $A K I$ acute kidney injury, VILI ventilator-induced lung injury, ICU intensive care unit

investigating its preventive role are inconclusive and more data are needed [79]. Inhaled NO transiently improves oxygenation and long term lung function in patients who survive, but does not affect mortality and may cause renal impairment, hence it is not recommended [80]. A neuromuscular blocker, cisatracurium besilate has shown some benefit when used for early ARDS [81]. Statins [82], beta-agonists [83], non-steroidal anti-inflammatory drugs (NSAIDs), and an antioxidant (procysteine [L-2-oxo-thiazolidie-4-carboxylic acid]) have failed to show benefit for ARDS. Surfactant replacement [84], neutrophil elastase inhibitors and anticoagulation have also all failed in clinical trials.

Biologics directed against TNF have been highly successful in rheumatoid arthritis, but no benefit has been seen for the treatment of inflammatory lung diseases, including ARDS $[85,86]$. With a view to lung regeneration, cellular therapies and intravenous mesenchymal stem cell therapy are in development for ARDS [87] [88]. There is significant interest in the targeted use of anti-inflammatory therapies in patients with ARDS defined by blood biomarker levels [89]. It is logical to study effects of anti-inflammatory agents in patients with hyper-inflammatory ARDS, and to tailor use of specific anti-inflammatory drugs to ARDS patients with particular biomarker profiles [90].
Despite intense investigation, no specific pharmacological treatment for ARDS has been shown to affect the mortality, even though preclinical trials in animal models have looked promising. Targeting a single pathogenetic pathway is not unlikely to be advantageous due to the complexity of the mechanisms involved.

However, the characterization of the ARDS subphenotype by blood biomarkers may help clinician to select patients who may benefit from specific therapeutic strategy and ultimately tailor the treatment on our single patient. In fact, it has been proved that a high PEEP strategy in ARDS patients affected major outcome only in the hyperinflammatory subphenotype [91]. Moreover the restrictive fluid strategy was beneficial in the same selected ARDS patients [47]. More studies are needed to further explore the benefits of different therapies based on particular ARDS biomarker profile.

\section{Conclusions}

ARDS is a syndrome still associated with high mortality. The main treatment in order to reduce mortality relies on the correct strategic use of mechanical ventilation aimed to protect the lung by avoiding the pro-inflammatory mechanisms triggered by mechanical ventilation. The latter, however, does not represent the real treatment of ARDS since it is aimed to preserve the 
respiratory exchange, preserving life and allowing physicians to wait for the resolution of the underlying disease. To further reduce mortality, the therapy of ARDS should be based on the inflammatory mechanisms responsible of the lung injury, possibly taking into account the genetic difference among patients and the origin of ARDS, such as the primary or the secondary ARDS.

\section{Abbreviations}

ACE: Angiotensin-converting enzyme; AECC: American-European Consensus Conference; AKI: Acute kidney injury; ALI: Acute Lung Injury; Ang2: Angiopoietin-2; ARDS: Acute Respiratory Distress Syndrome; BAL: Bronchoalveolar lavage; CAPSOD: Community Acquired Pneumonia and Sepsis Outcome Diagnostics; CC16: Clara cell 16 protein; CPAP: Continuous positive airway pressure; DAD: Diffuse alveolar damage; DNA: Desossiribonucleic Acid; ECMO: Extra-corporeal membrane oxygenation; EGDT: Early goal-directed therapy; GC-MS: Gas-chromatography and mass spectrometry; GWAS: Genome-wide association study; HFOV: High frequency oscillatory ventilation; ICU: Intensive Care unit; IFITM3: Interferoninducible transmembrane 3; IFN-Y: Interferon gamma; IL-10: Interleukin 10; IL1RA: Interleukin 1 receptor antagonist; IL-1B: Interleukin 1B; IL-6: Interleukin 6; IL-8: Interleukin 8; KGF: Keratinocyte growth factor; KGF: Keratinocyte growth factor; KL-6: Krebs von den Lungen-6; LC-MS: Liquid chromatography mass spectrometry; LIPS: Lung Injury Prediction Score; mRNA: Micro RiboNucleic Acid; MS: Mass spectrometry; NMR: Nuclear magnetic resonance; NO: Nitric oxide; NSAIDs: Non-steroidal anti-inflammatory drugs; PAI-1: Plasminogen activator inhibitor-1; $\mathrm{PaO}_{2} / \mathrm{FIO}_{2}$ : Oxygen arterial partial pressure/oxygen inspired fraction ratio; PEEP: Positive end-expiratory pressure; ProCESS: Protocolized Care of Early Septic Shock; RoCl: Registry of Critical IIIness; sFLT-1: Soluble fms-like tyrosine kinase 1; sICAM-1: Soluble intercellular adhesion molecule 1; SP: Surfactant protein; SPB: Surfactant protein B; SPD: Surfactant protein D; SRAGE: Soluble receptor for advanced glycation end-products; s-VEGFR: Soluble vascular endothelial growth factor receptor; TM: Thrombomodulin; TNFR 1: Tumor necrosis factor receptor 1; TNFR: Transforming Growth Factor Receptor; TNF-a: Transforming Growth Factor a; VEGF: Vascular endothelial growth factor; VILI: Ventilator-induced lung injury; VOCs: Volatile organic compounds; VWF: Von Willebrand factor

\section{Acknowledgements}

We will acknowledge the ERS Support. Dr. Savino Spadaro is the recipient of a European Respiratory Society fellowship - Number STRTF [2014-5316]. We thank Imperial's Health Protection Research Unit (HPRU) in Respiratory Infection and the National Institute for Health Research Imperial Biomedical Research Centre (NIHR Imperial BRC) at Imperial College Healthcare NHS Trust.

\section{Funding}

This study was supported by European Respiratory Society "ERS short term research training fellowship rules 2014".

\section{Availability of data and materials}

Data sharing not applicable to this article no datasets were generated or analysed during the current study.

\section{Authors' contributions}

SS, GC, TH and CT designed and drafted the manuscript. CT and PM carried out the literature search and revised the manuscript. PM, RT, TT, TM, RR and CAV drafted and revised the manuscript. All authors red and approved the final manuscript.

Ethics approval and consent to participate

Not applicable

\section{Consent for publication}

Not applicable

\section{Competing interests}

The authors declare that they have not competing interests.

\section{Publisher's Note}

Springer Nature remains neutral with regard to jurisdictional claims in published maps and institutional affiliations.

\section{Author details}

'Department of Morphology, Surgery and Experimental Medicine, Intensive Care Section, University of Ferrara, 44121 Ferrara, Italy. ${ }^{2}$ Faculty of Medicine, National Heart and Lung Institute, Imperial College London, London, UK. ${ }^{3}$ Department of Anesthesia, Critical Care and Emergency, Fondazione IRCCS $\mathrm{Ca}^{\prime}$ Granda Ospedale Maggiore Policlinico, Milan, Italy. ${ }^{4}$ Unità Operativa Complessa di Pneumologia, Dipartimento di Scienze Biomediche, Odontoiatriche e delle Immagini Morfologiche e Funzionali (BIOMORF), Università di Messina, Messina, Italy.

Received: 11 August 2018 Accepted: 22 November 2018 Published online: 15 January 2019

\section{References}

1. Ashbaugh DG, Bigelow DB, Petty TL, Levine BE. Acute respiratory distress in adults. Lancet. 1967;2:319-23.

2. Bernard GR, Artigas A, Brigham KL, Carlet J, Falke K, Hudson L, Lamy M, Legall JR, Morris A, Spragg R. The American-European Consensus Conference on ARDS. Definitions, mechanisms, relevant outcomes, and clinical trial coordination. Am J Respir Crit Care Med. 1994;149:818-24.

3. Ranieri VM, Rubenfeld GD, Thompson BT, Ferguson ND, Caldwell E, Fan E, Camporota L, Slutsky AS, Force ADT. Acute respiratory distress syndrome: the Berlin definition. JAMA. 2012;307:2526-33.

4. Rubenfeld GD, Caldwell E, Peabody E, Weaver J, Martin DP, Neff M, Stern EJ, Hudson LD. Incidence and outcomes of acute lung injury. N Engl J Med. 2005;353:1685-93.

5. Koh Y. Update in acute respiratory distress syndrome. J Intensive Care. 2014;2:2

6. Bellani G, Laffey JG, Pham T, Fan E, Brochard L, Esteban A, Gattinoni L, van Haren F, Larsson A, McAuley DF, et al. Epidemiology, patterns of care, and mortality for patients with acute respiratory distress syndrome in intensive care units in 50 countries. JAMA. 2016;315:788-800.

7. Thompson BT, Chambers RC, Liu KD. Acute respiratory distress syndrome. N Engl J Med. 2017;377:1904-5.

8. Matthay MA, Ware LB, Zimmerman GA. The acute respiratory distress syndrome. J Clin Invest. 2012;122:2731-40.

9. Castro CY. ARDS and diffuse alveolar damage: a pathologist's perspective. Semin Thorac Cardiovasc Surg. 2006;18:13-9.

10. Blondonnet R, Constantin J-M, Sapin V, Jabaudon M. A pathophysiologic approach to biomarkers in acute respiratory distress syndrome. Dis Markers. 2016;2016:1-20

11. Thille AW, Esteban A, Fernández-Segoviano P, Rodriguez JM, Aramburu JA, Vargas-Errázuriz P, Martín-Pellicer A, Lorente JA, Frutos-Vivar F. Chronology of histological lesions in acute respiratory distress syndrome with diffuse alveolar damage: a prospective cohort study of clinical autopsies. Lancet Respir Med. 2013;1:395-401.

12. Marshall RP, Bellingan G, Webb S, Puddicombe A, Goldsack N, McAnulty RJ, Laurent GJ. Fibroproliferation occurs early in the acute respiratory distress syndrome and impacts on outcome. Am J Respir Crit Care Med. 2000;162: 1783-8.

13. Calfee CS, Delucchi K, Parsons PE, Thompson BT, Ware LB, Matthay MA, Thompson T, Ware LB, Matthay MA. Subphenotypes in acute respiratory distress syndrome: latent class analysis of data from two randomised controlled trials. Lancet Respir Med. 2014;2:611-20.

14. Spadaro S, Kozhevnikova I, Casolari P, Ruggeri P, Bellini T, Ragazzi R, Barbieri F, Marangoni E, Caramori G, Volta CA. Lower airways inflammation in patients with ARDS measured using endotracheal aspirates: a pilot study. BMJ Open Respir Res. 2017;4:e000222.

15. Sweeney TE, Khatri P. Generalizable biomarkers in Critical Care: Toward precision medicine. Crit Care Med. 2017;45:934-9.

16. Doyle IR, Bersten AD, Nicholas TE. Surfactant proteins-a and -B are elevated in plasma of patients with acute respiratory failure. Am J Respir Crit Care Med. 1997;156:1217-29.

17. Greene KE, Wright JR, Steinberg KP, Ruzinski JT, Caldwell E, Wong WB, Hull W, Whitsett JA, Akino T, Kuroki Y, et al. Serial changes in surfactantassociated proteins in lung and serum before and after onset of ARDS. Am J Respir Crit Care Med. 1999;160:1843-50. 
18. Ware LB, Koyama T, Billheimer DD, Wu W, Bernard GR, Thompson BT, Brower RG, Standiford TJ, Martin TR, Matthay MA, Bernard GR. Prognostic and pathogenetic value of combining clinical and biochemical indices in patients with acute lung injury. Chest. 2010;137:288-96.

19. Eisner MD, Parsons P, Matthay MA, Ware L, Greene K. Plasma surfactant protein levels and clinical outcomes in patients with acute lung injury. Thorax. 2003;58:983-8.

20. Sato H, Callister MEJ, Mumby S, Quinlan GJ, Welsh KI, DuBois RM, Evans TW. $\mathrm{KL}-6$ levels are elevated in plasma from patients with acute respiratory distress syndrome. Eur Respir J. 2004;23:142-5.

21. Terpstra ML, Aman J, van Nieuw Amerongen GP, Groeneveld AB. Plasma biomarkers for acute respiratory distress syndrome: a systematic review and meta-analysis*. Crit Care Med. 2014;42:691-700.

22. Koh H, Tasaka S, Hasegawa N, Asano K, Kotani T, Morisaki H, Takeda J, Fujishima S, Matsuda T, Hashimoto S, Ishizaka A. Vascular endothelial growth factor in epithelial lining fluid of patients with acute respiratory distress syndrome. Respirology. 2008;13:281-4.

23. Stern JB, Fierobe L, Paugam C, Rolland C, Dehoux M, Petiet A, Dombret MC, Mantz J, Aubier M, Crestani B. Keratinocyte growth factor and hepatocyte growth factor in bronchoalveolar lavage fluid in acute respiratory distress syndrome patients. Crit Care Med. 2000;28:2326-33.

24. Uchida T, Shirasawa M, Ware LB, Kojima K, Hata Y, Makita K, Mednick G, Matthay ZA, Matthay MA. Receptor for advanced glycation end-products is a marker of type I cell injury in acute lung injury. Am J Respir Crit Care Med. 2006:173:1008-15.

25. Shirasawa M, Fujiwara N, Hirabayashi S, Ohno H, Lida J, Makita K, Hata Y. Receptor for advanced glycation end-products is a marker of type I lung alveolar cells. Genes Cells. 2004;9:165-74.

26. Jabaudon M, Blondonnet R, Roszyk L, Bouvier D, Audard J, Clairefond G, Fournier M, Marceau G, Déchelotte P, Pereira B, et al. Soluble receptor for advanced glycation end-products predicts impaired alveolar fluid clearance in acute respiratory distress syndrome. Am J Respir Crit Care Med. 2015;192:191-9.

27. Ware LB, Calfee CS. Biomarkers of ARDS: what's new? Intensive Care Med. 2016:42:797-9

28. Determann RM, AANM R, Haitsma JJ, Zhang H, Slutsky AS, Ranieri VM, Schultz MJ. Plasma levels of surfactant protein $D$ and $\mathrm{KL}-6$ for evaluation of lung injury in critically ill mechanically ventilated patients. BMC Pulm Med. 2010;10:6-6.

29. Agrawal A, Matthay MA, Kangelaris KN, Stein J, Chu JC, Imp BM, Cortez A, Abbott J, Liu KD, Calfee CS. Plasma angiopoietin-2 predicts the onset of acute lung injury in critically ill patients. Am J Respir Crit Care Med. 2013; 187:736-42.

30. Hendrickson CM, Matthay MA. Endothelial biomarkers in human sepsis: pathogenesis and prognosis for ARDS. Pulm Circ. 2018;8:2045894018769876.

31. Xing K, Murthy S, Liles WC, Singh JM. Clinical utility of biomarkers of endothelial activation in sepsis-a systematic review. Crit Care. 2012;16:R7.

32. Wada T, Jesmin S, Gando S, Yanagida Y, Mizugaki A, Sultana SN, Zaedi S, Yokota $\mathrm{H}$. The role of angiogenic factors and their soluble receptors in acute lung injury (ALI)/ acute respiratory distress syndrome (ARDS) associated with critical illness. J Inflamm (London England). 2013;10:6-6.

33. Fremont RD, Koyama T, Ph D, Calfee CS, Wu W, Dossett LA, Bossert FR, Mitchell D, Wickersham N, Bernard GR, et al. Acute lung injury in patients with traumatic injuries: utility of a panel of biomarkers for diagnosis and pathogenesis. J Trauma. 2010;68:1121-7.

34. Calfee CS, Ware LB, Glidden DV, Eisner MD, Parsons PE, Thompson BT, Matthay MA. Use of risk reclassification with multiple biomarkers improves mortality prediction in acute lung injury. Crit Care Med. 2011;39:711-7.

35. Ware LB, Eisner MD, Thompson BT, Parsons PE, Matthay MA. Significance of Von Willebrand factor in septic and nonseptic patients with acute lung injury. Am J Respir Crit Care Med. 2004;170:766-72.

36. Binnie A, Tsang JLY, Dos Santos CC. Biomarkers in acute respiratory distress syndrome. Curr Opinion Critical Care. 2014:20:47-55.

37. Dolinay T, Kim YS, Howrylak J, Hunninghake GM, An CH, Fredenburgh L, Massaro AF, Rogers A, Gazourian L, Nakahira K, et al. Inflammasomeregulated cytokines are critical mediators of acute lung injury. Am J Respir Crit Care Med. 2012;185:1225-34.

38. Zhao Z, Wickersham N, Kangelaris KN, May AK, Bernard GR, Matthay MA, Calfee CS, Koyama T, Ware LB. External validation of a biomarker and clinical prediction model for hospital mortality in acute respiratory distress syndrome. Intensive Care Med. 2017:43:1123-31.

39. Moalli R, Doyle JM, Tahhan HR, Hasan FM, Braman SS, Saldeen T. Fibrinolysis in critically ill patients. Am Rev Respir Dis. 1989;140:287-93.
40. Prabhakaran P, Ware LB, White KE, Cross MT, Matthay MA, Olman MA. Elevated levels of plasminogen activator inhibitor-1 in pulmonary edema fluid are associated with mortality in acute lung injury. Am J Physiol Lung Cell Mol Physiol. 2003;285:L20-8.

41. Jalkanen V, Yang R, Linko R, Huhtala H, Okkonen M, Varpula T, Pettilä V, Tenhunen J. SuPAR and PAI-1 in critically ill, mechanically ventilated patients. Intensive Care Med. 2013;39:489-96.

42. Ware LB, Koyama T, Zhao Z, Janz DR, Wickersham N, Bernard GR, May AK, Calfee CS, Matthay MA. Biomarkers of lung epithelial injury and inflammation distinguish severe sepsis patients with acute respiratory distress syndrome. Crit Care. 2013;17(5):R253.

43. Brown RM, Semler MW, Zhao Z, Koyama T, Janz D, May KA, et Al. Plasma Angiopoietin-2 (Ang2) and Receptor for Advanced Glycation End Products (RAGE) Improve Diagnosis of ARDS Compared to Provider Clinical Assessment in Adult Trauma Patients. American Journal repsoratory Critical Care Medicine. 2015;191:A1617.

44. Calfee CS, Janz DR, Bernard GR, May AK, Kangelaris KN, Matthay MA, Ware LB. Distinct molecular phenotypes of direct versus indirect ARDS in single and multi-center studies. Chest. 2015;147:1539-48.

45. Bos LD, Schouten LR, van Vught LA, Wiewel MA, Ong DSY, Cremer O, Artigas A, Martin-Loeches I, Hoogendijk AJ, van der Poll T, et al. Identification and validation of distinct biological phenotypes in patients with acute respiratory distress syndrome by cluster analysis. Thorax. 2017;72:876-83.

46. Delucchi K, Famous KR, Ware LB, Parsons PE, Thompson BT, Calfee CS, Network A. Stability of ARDS subphenotypes over time in two randomised controlled trials. Thorax. 2018;73:439-45.

47. Famous KR, Delucchi K, Ware LB, Kangelaris KN, Liu KD, Thompson BT, Calfee CS, Network A. Acute respiratory distress syndrome subphenotypes respond differently to randomized fluid management strategy. Am J Respir Crit Care Med. 2017;195:331-8.

48. Hou PC, Filbin MR, Wang H, Ngo L, Huang DT, Aird WC, Yealy DM, Angus DC, Kellum JA, Shapiro NI, Pro Cl. Endothelial permeability and hemostasis in septic shock: results from the ProCESS trial. Chest. 2017;152:22-31.

49. Kellum JA, Pike F, Yealy DM, Huang DT, Shapiro NI, Angus DC. Relationship between alternative resuscitation strategies, host response and injury biomarkers, and outcome in septic shock: analysis of the protocol-based Care for Early Septic Shock Study. Crit Care Med. 2017;45:438-45.

50. Davies A, Jones D, Bailey M, Beca J, Bellomo R, Blackwell N, Forrest P, Gattas D, Granger E, Herkes R, et al. Extracorporeal Membrane Oxygenation for 2009 Influenza a(H1N1) acute respiratory distress syndrome. JAMA. 2009;302:1888-95.

51. Peek GJ, Mugford M, Tiruvoipati R, Wilson A, Allen E, Thalanany MM, Hibbert $\mathrm{CL}$, Truesdale A, Clemens F, Cooper N, et al. Efficacy and economic assessment of conventional ventilatory support versus extracorporeal membrane oxygenation for severe adult respiratory failure (CESAR): a multicentre randomised controlled trial. Lancet. 2009;374:1351-63.

52. Everitt AR, Clare S, Pertel T, John SP, Wash RS, Smith SE, Chin CR, Feeley EM, Sims JS, Adams DJ, et al. IFITM3 restricts the morbidity and mortality associated with influenza. Nature. 2012;484:519-23.

53. Rogers AJ, Matthay MA. Applying metabolomics to uncover novel biology in ARDS. Am J Phys Lung Cell Mol Phys. 2014;306:L957-61.

54. Stringer KA, McKay RT, Karnovsky A, Quémerais B, Lacy P. Metabolomics and its application to acute lung diseases. Front Immunol. 2016;7:44.

55. Wishart DS, Jewison T, Guo AC, Wilson M, Knox C, Liu Y, Djoumbou Y, Mandal R, Aziat F, Dong E, et al. HMDB 3.0-The Human Metabolome Database in 2013. Nucleic Acids Res. 2013:41.

56. Bos LDJ. Diagnosis of acute respiratory distress syndrome by exhaled breath analysis. Ann Transl Med. 2018;6:33.

57. Stringer KA, Serkova NJ, Karnovsky A, Guire K, Paine R, Standiford TJ. Metabolic consequences of sepsis-induced acute lung injury revealed by plasma $1 \mathrm{H}$-nuclear magnetic resonance quantitative metabolomics and computational analysis. AJP Lung Cell Mol Physiol. 2011;300:L4-L11.

58. Langley RJ, Tsalik EL, Van Velkinburgh JC, Glickman SW, Rice BJ, Wang C, Chen B, Carin L, Suarez A, Mohney RP, et al. Sepsis: an integrated clinicometabolomic model improves prediction of death in sepsis. Sci Transl Med. 2013;5:195ra95.

59. Slupsky CM, Rankin KN, Fu H, Chang D, Rowe BH, Charles PG, McGeer A, Low D, Long R, Kunimoto D, et al. Pneumococcal pneumonia: potential for diagnosis through a urinary metabolic profile. J Proteome Res. 2009:8:5550-8.

60. Mathru M, Rooney MW, Dries DJ, Hirsch LJ, Barnes L, Tobin MJ. Urine hydrogen peroxide during adult respiratory distress syndrome in patients with and without sepsis. Chest. 1994;105:232-6. 
61. McClintock DE, Ware LB, Eisner MD, Wickersham N, Thompson BT, Matthay MA. National Heart In, and blood institute ARDS network: higher urine nitric oxide is associated with improved outcomes in patients with acute lung injury. Am J Respir Crit Care Med. 2007;175:256-62.

62. Schmidt EP, Overdier KH, Sun X, Lin L, Liu X, Yang Y, Ammons LA, Hiller TD, Suflita MA, Yu Y, et al. Urinary Glycosaminoglycans predict outcomes in septic shock and acute respiratory distress syndrome. Am J Respir Crit Care Med. 2016;194:439-49.

63. Sweeney TE, Thomas NJ, Howrylak JA, Wong HR, Rogers AJ, Khatri P. Multicohort analysis of whole-blood gene expression data does not form a robust diagnostic for acute respiratory distress syndrome. Crit Care Med. 2018;46:244-51.

64. Sweeney TE, Azad TD, Donato M, Haynes WA, Perumal TM, Henao R, Bermejo-Martin JF, Almansa R, Tamayo E, Howrylak JA, et al. Unsupervised analysis of transcriptomics in bacterial Sepsis across multiple datasets reveals three robust clusters. Crit Care Med. 2018;46:1-1.

65. Ferruelo A, Peñuelas Ó, Lorente JA. MicroRNAs as biomarkers of acute lung injury. Ann Transl Med. 2018;6:34.

66. Cardinal-Fernández P, Ferruelo A, Esteban A, Lorente JA. Characteristics of microRNAs and their potential relevance for the diagnosis and therapy of the acute respiratory distress syndrome: From bench to bedside. Transl Res. 2016;169:102-11.

67. Roderburg C, Luedde M, Vargas Cardenas D, Vucur M, Scholten D, Frey N, Koch A, Trautwein C, Tacke F, Luedde T. Circulating microRNA-150 serum levels predict survival in patients with critical illness and sepsis. PLoS One. 2013;8:e54612

68. Han Y, Li Y, Jiang Y. The prognostic value of plasma MicroRNA-155 and MicroRNA-146a level in severe Sepsis and Sepsis-induced acute lung injury patients. Clin Lab. 2016;62:2355-60.

69. Zhu Z, Liang L, Zhang R, Wei Y, Su L, Tejera P, Guo Y, Wang Z, Lu Q, Baccarelli $A A$, et al. Whole blood microRNA markers are associated with acute respiratory distress syndrome. Intensive Care Med Exp. 2017:5:38.

70. Meyer NJ, Christie JD. Genetic heterogeneity and risk of acute respiratory distress syndrome. Semin Respir Crit Care Med. 2013;34:459-74.

71. Christie JD, Wurfel MM, Feng R, O'Keefe GE, Bradfield J, Ware LB, Christiani DC, Calfee CS, Cohen MJ, Matthay M, et al. Genome wide association identifies PPFIA1 as a candidate gene for acute lung injury risk following major trauma. PLoS One. 2012;7:e28268.

72. Yadav $H$, Thompson BT, Gajic O. Fifty years of research in ARDS. Is acute respiratory distress syndrome a preventable disease? Am J Respir Crit Care Med. 2017; 195:725-36

73. Wohlrab P, Kraft F, Tretter V, Ullrich R, Markstaller K, Klein KU. Recent advances in understanding acute respiratory distress syndrome. F1000Res. 2018;7:263.

74. Fan E, Brodie D, Slutsky AS. Acute respiratory distress syndrome: advances in diagnosis and treatment. JAMA. 2018;319:698-710.

75. Fan E, Del Sorbo L, Goligher EC, Hodgson CL, Munshi L, Walkey AJ, Adhikari NK, Amato MBP, Branson R, Brower RG, et al. An official American Thoracic Society/European Society of Intensive Care Medicine/Society of Critical Care Medicine clinical practice guideline: mechanical ventilation in adult patients with acute respiratory distress syndrome. Am J Respir Crit Care Med. 2017; 195:1253-63.

76. Investigators $P$, Rowan KM, Angus DC, Bailey M, Barnato AE, Bellomo R, Canter RR, Coats TJ, Delaney A, Gimbel E, et al. Early, goal-directed therapy for septic shock - a patient-level meta-analysis. N Engl J Med. 2017;376: 2223-34.

77. Steinberg KP, Hudson LD, Goodman RB, Hough CL, Lanken PN, Hyzy R, Thompson BT, Ancukiewicz M, National Heart L. Blood institute acute respiratory distress syndrome clinical trials $\mathrm{N}$ : efficacy and safety of corticosteroids for persistent acute respiratory distress syndrome. N Engl J Med. 2006;354:1671-84.

78. Festic E, Carr GE, Cartin-Ceba R, Hinds RF, Banner-Goodspeed V, Bansal V, Asuni AT, Talmor D, Rajagopalan G, Frank RD, et al. Randomized clinical trial of a combination of an inhaled corticosteroid and Beta agonist in patients at risk of developing the acute respiratory distress syndrome. Crit Care Med. 2017:45:798-805

79. Yadav $\mathrm{H}$, Kor DJ. Platelets in the pathogenesis of acute respiratory distress syndrome. Am J Physiol Lung Cell Mol Physiol. 2015;309:L915-23.

80. Gebistorf F, Karam O, Wetterslev J, Afshari A. Inhaled nitric oxide for acute respiratory distress syndrome (ARDS) in children and adults. Cochrane Database Syst Rev. 2016:CD002787.
81. Papazian L, Forel JM, Gacouin A, Penot-Ragon C, Perrin G, Loundou A, Jaber S, Arnal JM, Perez D, Seghboyan JM, et al. Neuromuscular blockers in early acute respiratory distress syndrome. N Engl J Med. 2010;363:1107-16.

82. National Heart L, Blood Institute ACTN, Truwit JD, Bernard GR, Steingrub J, Matthay MA, Liu KD, Albertson TE, Brower RG, Shanholtz C, et al. Rosuvastatin for sepsis-associated acute respiratory distress syndrome. N Engl J Med. 2014;370:2191-200.

83. Matthay MA, Brower RG, Carson S, Douglas IS, Eisner M, Hite D, Holets S, Kallet RH, Liu KD, Maclntyre N, et al. Randomized, placebo-controlled clinical trial of an aerosolized beta(2)-agonist for treatment of acute lung injury. Am Respir Crit Care Med. 2011;184:561-8.

84. Kim HC, Won Y-Y. Clinical, technological, and economic issues associated with developing new lung surfactant therapeutics. Biotechnol Adv. 2018; 36(4):1185-93.

85. Malaviya R, Laskin JD, Laskin DL. Anti-TNFa therapy in inflammatory lung diseases. Pharmacol Ther. 2017;180:90-8.

86. Boyle AJ, McNamee JJ, McAuley DF. Biological therapies in the acute respiratory distress syndrome. Expert Opin Biol Ther. 2014;14:969-81.

87. Wilson JG, Liu KD, Zhuo H, Caballero L, McMillan M, Fang X, Cosgrove K, Vojnik R, Calfee CS, Lee JW, et al. Mesenchymal stem (stromal) cells for treatment of ARDS: a phase 1 clinical trial. Lancet Respir Med. 2015;3:24-32.

88. Wang Y, Pati S, Schreiber M. Cellular therapies and stem cell applications in trauma. Am J Surg. 2018;215:963-72.

89. Thompson BT, Chambers RC, Liu KD. Acute respiratory distress syndrome. N Engl J Med. 2017;377:562-72.

90. Meyer NJ, Calfee CS. Novel translational approaches to the search for precision therapies for acute respiratory distress syndrome. Lancet Respir Med. 2017:5:512-23.

91. Calfee CS, Delucchi K, Parsons PE, Thompson BT, Ware LB, Matthay MA, Network NA. Subphenotypes in acute respiratory distress syndrome: latent class analysis of data from two randomised controlled trials. Lancet Respir Med. 2014;2:611-20.

92. Prescott HC, Calfee CS, Thompson BT, Angus DC, Liu VX. Toward smarter lumping and smarter splitting: rethinking strategies for Sepsis and acute respiratory distress syndrome clinical trial design. Am J Respir Crit Care Med. 2016;194:147-55.

93. Seymour CW, Gomez H, Chang CH, Clermont G, Kellum JA, Kennedy J, Yende S, Angus DC. Precision medicine for all? Challenges and opportunities for a precision medicine approach to critical illness. Crit Care. 2017;21:257.

94. Wiedemann HP, Wheeler AP, Bernard GR, Thompson BT, Hayden D, deBoisblanc B, Connors AF, Hite RD, Harabin AL. National Heart In, and blood institute acute respiratory distress syndrome (ARDS) clinical trials network: comparison of two fluid-management strategies in acute lung injury. N Engl J Med. 2006;354:2564-75.

95. Semler MW, Wheeler AP, Thompson BT, Bernard GR, Wiedemann HP, Rice TW. National Institutes of Health National Heart In, and blood institute acute respiratory distress syndrome network: impact of initial central venous pressure on outcomes of conservative versus Liberal fluid Management in Acute Respiratory Distress Syndrome. Crit Care Med. 2016:44:782-9.

96. Meduri GU, Bridges L, Shih MC, Marik PE, Siemieniuk RAC, Kocak M. Prolonged glucocorticoid treatment is associated with improved ARDS outcomes: analysis of individual patients' data from four randomized trials and trial-level meta-analysis of the updated literature. Intensive Care Med. 2016:42:829-40

\section{Ready to submit your research? Choose BMC and benefit from:}

- fast, convenient online submission

- thorough peer review by experienced researchers in your field

- rapid publication on acceptance

- support for research data, including large and complex data types

- gold Open Access which fosters wider collaboration and increased citations

- maximum visibility for your research: over $100 \mathrm{M}$ website views per year

At $\mathrm{BMC}$, research is always in progress.

Learn more biomedcentral.com/submission 